\title{
Radiculitis and its Current Approach
}

\author{
Dr.Avinash Shankar ${ }^{1 *}$, Dr.Amresh Shankar ${ }^{2}$, Dr Anuradha Shankar ${ }^{3}$ \\ ${ }^{I} M D$ (Internal Medicine), DNB(E\&M); PhD , Postgraduate in Endocrinology \& Metabolism(AIIMS-Delhi) \\ ,Chairman ,Institute of Applied Medicine,National Institute of Health \& Research \\ ,Warisaliganj(Nawada)Bihar, 805130 \\ ${ }^{2}$ BAMS(BRABU); MHA, Hon Director, Aarogyam Punarjeevan, Ram Bhawan, Ara Garden, Jagdeopath,Baily \\ Road ,Patna 14 \\ ${ }^{3} B A M S(B R A B U)$, ExDirector, Centre For Indigenous Medicine \& Research, Senior Research Fellow cum \\ Medical Officer,Regional Institute of Ayurveda Research, Itanagar (Arunachal)
}

\begin{abstract}
*Corresponding Author: Dr. Avinash Shankar, MD (Internal Medicine), DNB(E\&M); PhD, Postgraduate in Endocrinology \& Metabolism (AIIMS-Delhi), Chairman, Institute of Applied Medicine,National Institute of Health \& Research, Warisaliganj(Nawada)Bihar,805130
\end{abstract}

\begin{abstract}
Radiculitis, an agonizing painful condition is due to inflammation of the spinal nerve root or roots in the region of neural foramen and its presentation is termed as Radiculopathy which commonly affect the cervical and lumbar region

Incidence of lumbar radiculopathy is 5\% to more than $30 \%$ with a lifetime prevalence of $60 \%$ to $90 \%$ and cervical radiculopathy is 107.3 per 100,000 for men and 63.5 per 100,000 for women with a peak at 50 to 54 years of age.

Inspite of advancement in diagnostics i.e- CT scan and MRI and treatment with traction,surgical decompression and other adjuvant like neuro vitamin supplementation and analgesic antiarthritic supplementation satisfactory clinical response with improved quality of life reamain a challenge, thus a therapeutic regime combined with herbal neurotonic and neuro vigorative been evaluated in patients who failed to respond the present therapeutics
\end{abstract}

\section{Objective of study}

To assess the herbal neurogenic containing therapeutic regime ensuring clinical relief and improving quality of life in patients of radiculopathy

\section{Material \& Method}

718 diagnosed and already treated cases of radiculopathy attending at Centre for Critical Care, National Institute of Health \& Research Warisaliganj (Nawada)Bihar been selected, interrogated, examined clinically, assessed and analysed their previous investigation reports, therapeutics taken and their effect.

Irrespective of their clinical severity all patients were advocated the prescribed regime and were followed for post therapy 2 years for which patients been given a follow up card to record the changes.

\section{Result}

Patients of mild, moderate and severe grade of clinical presentation shows grade I clinical response with improved quality of life in $100 \%, 80.2 \%$ and $88.4 \%$ patients respectively, though $0.9 \%$ and $1.9 \%$ of moderate and severe grade of clinical severity fails to prove worth.

No patients of either status had alteration in bio parameters or any adversity during therapy or 2 years of post-therapy follow up .

Keywords: Radiculitis,Radiculopathy,cervical ,lumbar , CT ,MRI, herbal neurogenic, neurovigorative, quality of life

\section{INTRODUCTION}

Radiculitis synonym of radicular pain i.e.- alteration in sensation or muscle power produced due to inflammation of spinal nerve root Or roots in the region of neural foramen and its presentation is termed as Radiculopathy Or Pinched nerve with common presentation as - Pain, weakness, numbness or difficulty in controlling specific muscles ${ }^{1}$. On basis of its common area of involvement i.e.cervical and lumbar region it is also known as Cervical and lumbar Radiculitis or radiculopathy 

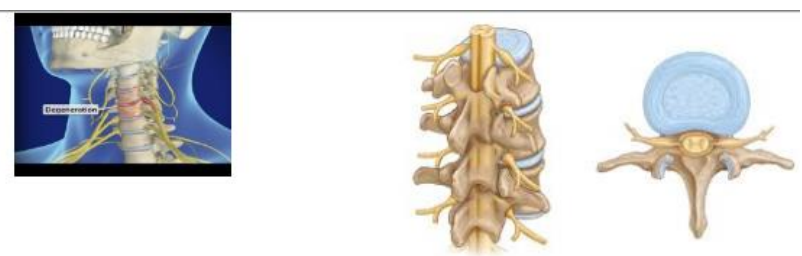

(Cervical radiculopathy)

(Lumbar radiculopathy )

The incidence of low back pain is estimated to be $5 \%$ to more than $30 \%$ with a lifetime prevalence of $60 \%$ to $90 \%$. Approximately $50 \%$ of cases will resolve within one to two weeks. $90 \%$ of cases will resolve in six to 12 weeks. The incidence of radicular symptoms in patients presenting with low back pain ranges from $12 \%$ to $40 \%$. While an annual incidence of cervical radiculopathy of 107.3 per 100,000 for men and 63.5 per 100,000 for women with a peak at 50 to 54 years of age. ${ }^{(2,3)}$

It is mechanical compression of nerve root usually at the exit foramen or lateral recess secondary to degenerative disc disease ,osteo arthritis, facet degeneration or hypertrophy, ligamentous hypertrophy ,spondylolisthesis or its combination though rarely also caused by radiation, diabetes mellitus, neoplastic disease Or any meningeal disease $e^{(4,5,6)}$

\begin{tabular}{|ll|}
\hline Common presentation & Preceding factors \\
Agonising pain in the back & Accidental injury \\
Pain during walking & Heavy weight lifting \\
Pain during changing posture & Recurrent fever \& debility \\
Pain in neck & Diabeties mellitus \\
Tingling numbness in the extremity & Post parturition in female \\
\hline
\end{tabular}

As per American College of Radiologyprojectional radiographyis an appropriate tool for initial study ,Magnetic resonance imaging (MRI) of the portion of the spine . Electrodiagnostic testing, consisting of NCS (nerve conduction study) and EMG (electromyography), aremore significant and specific diagnostic tool to ascertain nerve root injury. Needle EMG is considered most sensitive tool to reveal active denervation in the distribution of the involved nerve root, and neurogenic-appearing voluntary motor units in more chronic radiculopathies $(7,8,9)$

Present therapeutics i.e.- traction, cervical collar or abdominal belt ,transdermal steroid injection , epidural injection, analgesics, calcium supplementation, vitamin D3 supplementation, fails to ensure cure in all the cases thus a therapeutic regime containing herbal neuro rejuvenator been evaluated for its clinical efficacy and safety profile.$(10,11,12,13,14)$

\section{Objective of the study}

Ascertain clinical efficacy and safety profile of herbal neuro rejuvenator containing regime in patients of radiculitis non responsive to existing therapeutics .

\section{Duration of study}

January 1014 to December 2016 with 2 years rigorous follow up from January 2017-December 2018 for post therapy symptom withdrawal or any drug adversity .

\section{Material \& Methods}

\section{Material}

Patients of radiculopathy treated and non responsive to present therapeutics attending Centre For Critical Care National Institute Of Health \& Research

Warisaliganj were selected for evaluation of the present therapeutic regime clinical efficacy and safety profile .

\section{Methods:}

Selected patients and their attendants were thoroughly interrogated for onset of disease ,clinical presentation ,therapeutics taken and their response , any untoward effect or exacerbation of clinical presentation, preceding factors ,clinically examined (Sparling's test for Cervical radiculitis and Straight leg raising test (SLR) for lumbar radiculitis . In addition, deep tendon reflex (Stretch reflex) was also elucidated. ${ }^{(15,16)}$ 
As selected patients were already under gone for various investigation X-ray of the region ,MRI, Test for tuberculosis ,blood sugar and other haematological test hence basic bio parameters were repeated to adjudge the drug adversity on haematological, hepatic and renal parameters .

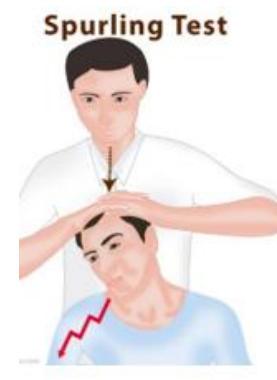

(SpurlingTest)

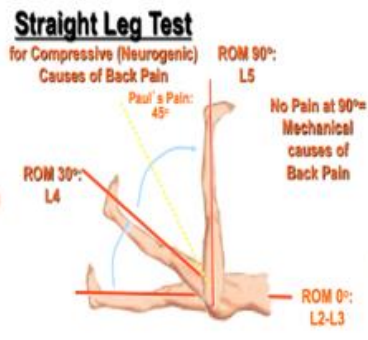

(Straight Leg Raising Test)

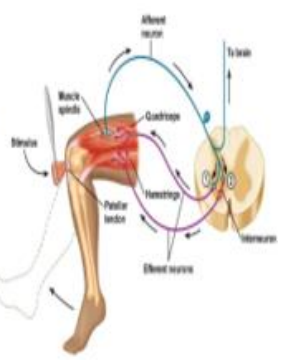

(Stretch reflex)

The Spurling test is a medical maneuver to assess nerve root pain (also known as radicular pain). The examiner turns the patient's head to the affected side while extending and applying downward pressure to the top of the patient's head. A positive Spurling's sign is when the pain arising in the neck radiates in the direction of the corresponding dermatomeipsilaterally. It is a type of cervical compression test

The straight leg raise, also called Lasègue's sign, Lasègue test or Lazarević's sign, is a test done during a physical examination to determine whether a patient with low back pain has an underlying herniated disc, often located at L5 (fifth lumbar spinal nerve).

The selected patients were classified in three groups as per their severity i.e. mild ,moderate and severe

\begin{tabular}{|l|l|}
\hline Severity Grade & Characteristics \\
\hline Mild & Pain in the affected region (Shoulder /back) \\
\hline Moderate & $\begin{array}{l}\text { Pain ,tingling and numbness, inability to move upper } \\
\text { Extremity }\end{array}$ \\
\hline Severe & $\begin{array}{l}\text { Agonizing pain, tingling and numbness, inability to } \\
\text { walk And raise upper extremity }\end{array}$ \\
\hline
\end{tabular}

Patients irrespective of their severity grade in addition to -

- Advise of remain pure vegetarian to avoid any hyperlipidaemia

- Exercise to maintain the joint mobility

Prescribed the following therapeutic regime containing -

- Inj. Calcium Gluconate 1 ampoule every $15^{\text {th }}$ day intravenous very slow

- Inj. Methyl cobalamin 1000mcg, Niacin 100mg, Pyridoxin 100mg and D Panthenol 50mg plus Betamethasone $2 \mathrm{mg}$ intravenous every $4^{\text {th }}$ day

- Syr. NEUROVIT $10 \mathrm{ml}$ every 12 hours orally

- Local application of MYONEUROL oil for transdermal absorption

- Anti arthritic analgesics (AcceclofenacSodium ) 100mg with muscle relaxant 12 hourly Orally

- Cap Vitamin D3 (Cholecalciferol ) 60K every week

\begin{tabular}{|l|l|}
\hline \multicolumn{2}{|c|}{ Each 5ml of Neurovit syrup constitutes } \\
\hline Acoruscalamus & $100 \mathrm{mg}$ \\
\hline Herpestismonneiri & $100 \mathrm{mg}$ \\
\hline EvolvulusAlsenoides & $100 \mathrm{mg}$ \\
\hline NardostachysJatamansi & $100 \mathrm{mg}$ \\
\hline Cassia acuitifolia Each 30ml ofMyoneurol Oil constitutes active constituents of \\
\hline \multicolumn{2}{|c|}{$100 \mathrm{mg}$} \\
\hline Dhatura & $2 \mathrm{gm}$ \\
\hline Punarnava & $1 \mathrm{gm}$ \\
\hline Sahjanchhal & $1 \mathrm{gm}$ \\
\hline Gandhprasarni & $1 \mathrm{gm}$ \\
\hline Lahsun & $1 \mathrm{gm}$ \\
\hline
\end{tabular}




\begin{tabular}{|l|l|}
\hline Kuchla & $1 \mathrm{gm}$ \\
\hline Jatamanshi & $1 \mathrm{gm}$ \\
\hline Chitrak & $1 \mathrm{gm}$ \\
\hline Mashkalayee & $1 \mathrm{gm}$ \\
\hline Shunthi & $4 \mathrm{gm}$ \\
\hline Amarlata & $0.5 \mathrm{gm}$ \\
\hline Ashvagandha & $1 \mathrm{gm}$ \\
\hline Kuth & $1 \mathrm{gm}$ \\
\hline
\end{tabular}

Patients were evaluated for duration required for relief in clinical presentation and to adjudge safety profile bio parameters were repeated every 3 months and at the end of therapy. In addition each patients were give a follow up card to enter the date of relief of presentation and nay untoward effects

Based on the clinical improvement therapeutic efficacy was graded as

\begin{tabular}{|l|l|}
\hline \multicolumn{1}{|c|}{ Clinical grade } & \multicolumn{1}{c|}{ Characteristics } \\
\hline Grade I & $\begin{array}{l}\text { Complete absence of presenting feature in } 6 \text { months of } \\
\text { therapy without any untoward effects, drug adversity } \\
\text { or withdrawal }\end{array}$ \\
\hline Grade II & $\begin{array}{l}\text { Complete absence of presenting symptoms and sign } \\
\text { needing > 1 yr of therapy without any untoward } \\
\text { effects, adversity or withdrawal }\end{array}$ \\
\hline Grade III & Only symptomatic relief with withdrawal presentation \\
\hline
\end{tabular}

\section{OBSERVATION}

Selected patients were of age group 15-above $>50$ yrs out of them $2.22 \%$ were of $15-20$ years while $27.8 \%$ were of age $>50$ years (Table-1)) and $434(60.4 \%$ ) were male and $284(39.6 \%)$ female (Figure 1)

Out of all $5.4 \%$ (39) were suffering since <1year while $23.8 \%(171)$ were since $>5$ years (Figure -2 ); 76(10.6\% ),212 (29.5 \%) and 430(59.9\% ) were of mild ,moderate and severe degree presentation respectively (Figure -3). 404 ( 210 male and 194 female ) were suffering with lumbar radiculitis and 314 (224 male and 90 female)with cervical radiculitis (Figure -4); 94.7\%(680) were non vegetarian and 5.3\%(38) were pure vegetarian (Figure -5);204(28.4\%) were with <IBW and $318(44.3 \%$ ) with $>$ IBW (Figure-6)

Clinical improvement was observed by $4^{\text {th }}$ week in 4 patients of mild, while by $6^{\text {th }}$ week in 6 and 97 patients of moderate and severe grade of severity. all patients of mild grade by $14^{\text {th }}$ week while 210 and 420 patients of moderate and severe grade by $20^{\text {th }}$ week of therapy (Figure -7)

All of mild grade severity achieved grade I clinical recovery while only 170 and 380 of moderate and severe grade of clinical severity respectively (figure -8). All cases of either mild moderate and severe grade of clinical severity had radiological improvement except 02 and 08 cases of moderate and severe grade remain unchanged. No patients of either status had any change in bioparameters during therapy and 2 years of post-therapy follow up. (Table- 2 )

In short observation can be summarized as-

\section{RADICULOPTHY}

(718)

\section{Cervical Radiculopathy}

\section{4}

\section{Mild}

\section{6}

All by $14^{\text {th }}$ week

Started in $4^{\text {th }}$ week

Grade I -76

Grade II - 0

Grade III- 0
Moderate

212

$99 \%$ by $20^{\text {th }}$ week

$6^{\text {th }}$ week

170

40

$\mathrm{O} 2$

\section{Lumbar Radiculopathy}

\section{4}

Severe

430

$97.4 \%$ by $20^{\text {th }}$ week

$6^{\text {th }}$ week

380

42

08 


\section{DISCUSSION}

Radiculitis, an agonising painful condition due to pinching of spinal nerve root at the exit or in vertebral spine is increasing these days may be due to emergence of non nutrient in diet changing life style predisposing for cholecalciferol compromise resulting in degenerative process.

Our spine constitutes 24 bones termed as vertebrae and are stacked one over other and connect to create a canal to protect the spinal cord

Spinal cord and nerves. an "electrical cables" travel through the spinal canal carrying messages between brain and muscles. Nerve roots branch came out from the spinal cord through openings in the vertebrae (foramen).

In between the vertebrae are flexible intervertebral discs which act as shock absorbers during movement or walking or running Intervertebral disks are flat, round, about $1.25 \mathrm{~cm}$ thick and are made up of two components:

- Annulus fibrosus. This is the tough, flexible outer ring of the disk.

- Nucleus pulposus. This is the soft, jelly-like center of the disk.

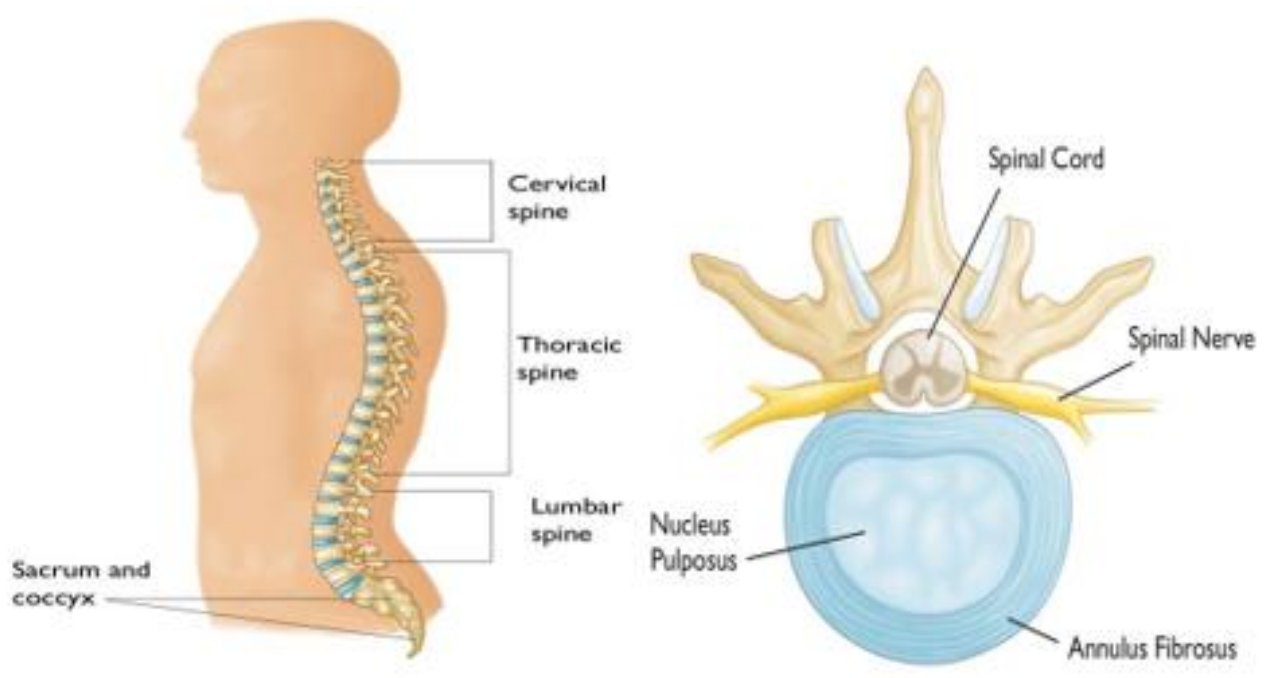

Thus any change in the intervertebral disc or adjacent bony part of vertebrae will compress the emerging nerve and cause inflammation of nerve resulting in agonizing pain full condition, also termed as Radiculopathy, which can affect cervical,thoracic and lumbar vertebral spine but out of them commonest are cervical and lumbar radiculopathy

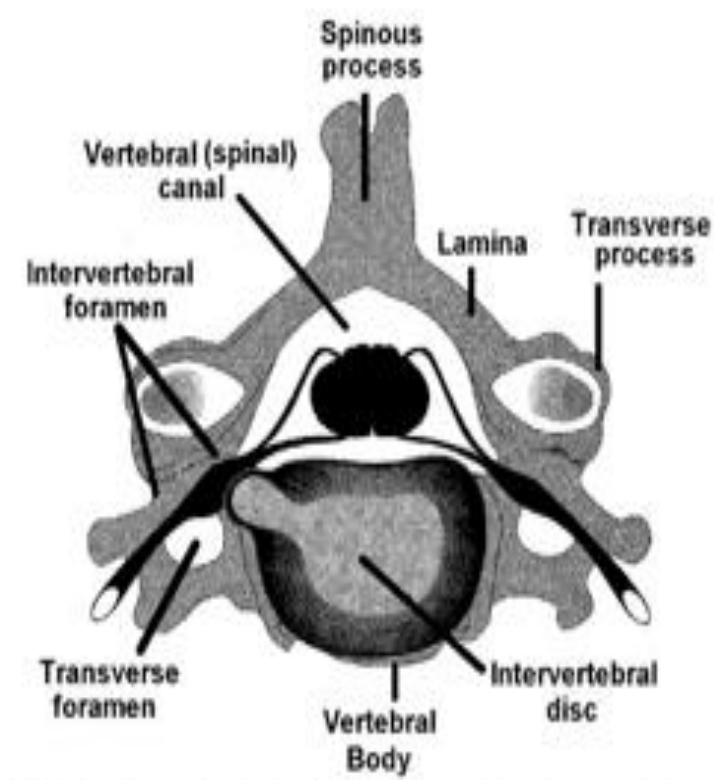

Far lateral cervical disc herniation causes compression of the nerve and the dersal root ganglion

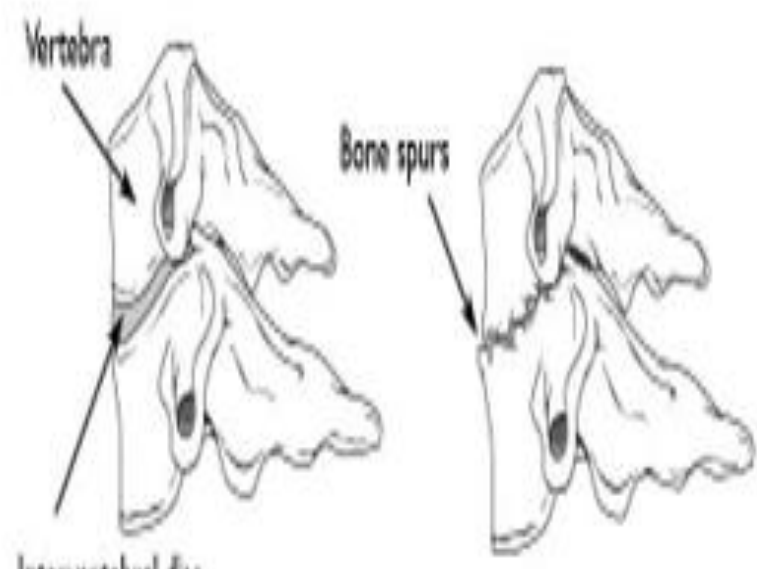




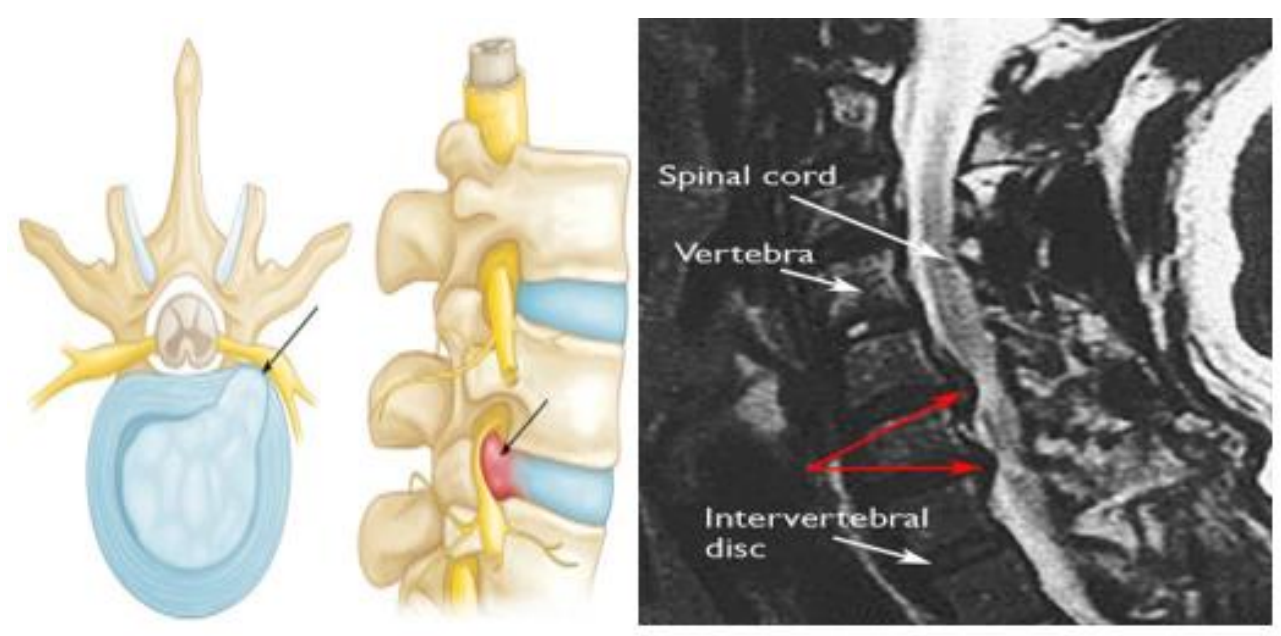

The commonest investigation to confirm the lesion are X-ray ,CT and MRI of the vertebral column .

The common conventional treatment only ensure transient pain relief and 718 cases of all ready treated cases with persistent agonising state of mild, moderate and severe grade of clinical presentation shows grade I clinical response with improved quality of life in 100\%,80.2\% and $88.4 \%$ patients respectively, though $0.9 \%$ and $1.9 \%$ of moderate and severe grade of clinical severity fails to prove worth .

No patients of either status had alteration in bio parameters or any adversity during therapy or 2 years of post therapy follow up .

This clinical achievement of the present therapeutic regime can be explained as ${ }^{17}$ -

Betamethasone acting as anti inflammatory reduces neural edema synergized by Intravenous Calcium administration whose inclusion of one mole exit 2 mole of Sodium acting on Sodium potassium ATPase pump and facilitate decrease in neural edema and calcium ion improves neural conduction .

In addition supplementation of Calcium and cholecalciferol ensure baone repair by oesteogenesis and check degenerative changes .

Methyl cobalamine, pyridoxine, Niacin and pantothenic acid support neural cells in its normal neural conduction and Neurovit a herbal composite by its neurogenic activity helps in restoration of neural viability and vitality which combinely ensure relief in pain ,neuropathic manifestation, Oral aceclofenac with muscle relaxant relieve agonizing pain while transdermal absorption of active constituent of Myoneurol oil helps ensure sustained pain relief .

Exercise facilitates mobility at the particular vertebral joints and sooth painful agony .

Thus bioregulatedosteogenesis and neural function by reducing neural edema and repairing joint facets, ensure sustained therapeutic out come and improved quality of life .

\section{CONCLUSION}

Present therapeutic regime constituting intravenous Calcium gluconate, Methylcobalamine, pyridoxine, niacin and D panthenol with Betamethasone 2mg intravenous, Cholecalciferol ,Herbal neuragen and transdermal neurotrope local application with active and passive exercise proves worth in management of Radiculopathy .

\section{TABLES \& LEGENDS}

Table1. number of patients

\begin{tabular}{|c|c|c|c|c|}
\hline Age group & \multicolumn{4}{|c|}{ Number of patients } \\
\hline In years & Male & Female & Total & Percent \\
\hline $15-20$ & 10 & 06 & 16 & 2.22 \\
\hline $20-25$ & 20 & 12 & 32 & \\
\hline $25-30$ & 30 & 18 & 48 & \\
\hline $30-35$ & 32 & 14 & 56 & \\
\hline $35-40$ & 70 & 42 & 112 & \\
\hline $40-45$ & 68 & 40 & 108 & \\
\hline $45-50$ & 88 & 58 & 146 & 27.8 \\
\hline$>50$ & 116 & 84 & 200 & \\
\hline & $434(60.4)$ & $284(39.6)$ & & \\
\hline
\end{tabular}


Pie diagram showing male:female composition

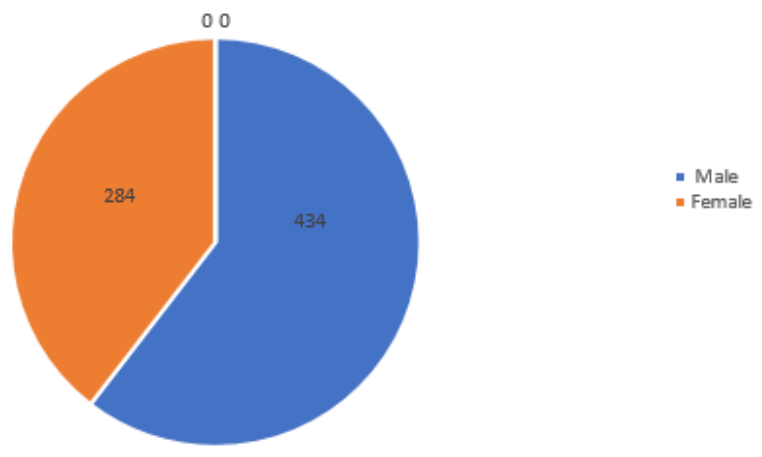

Figure1. Pie diagram showing male: female composition

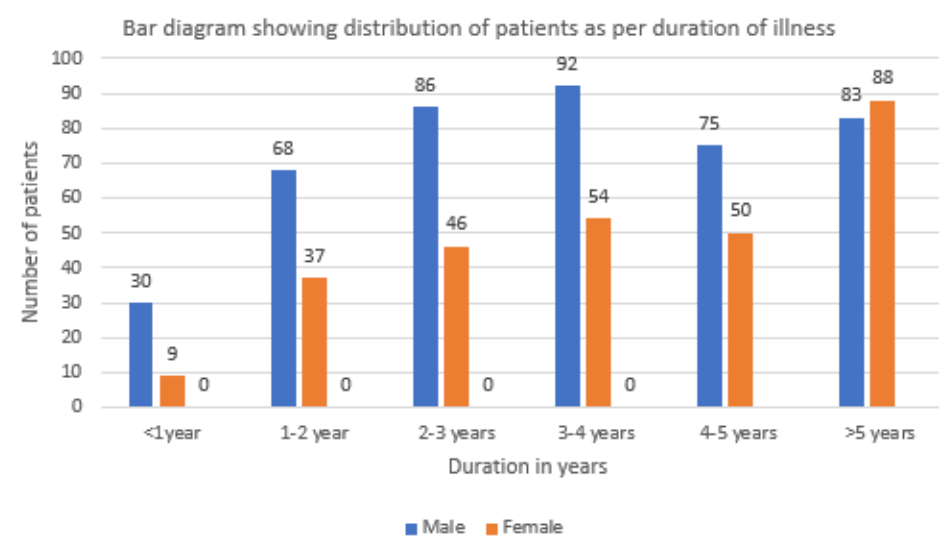

Figure2. Bar diagram showing distribution of patients as per duration of illness Pie diagram showin distribution of patient as per severity of illness

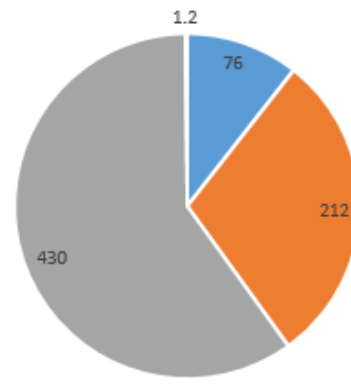

" Mild " Moderate |n severe

Figure3. Pie diagram showing distribution of patient as per disease stat

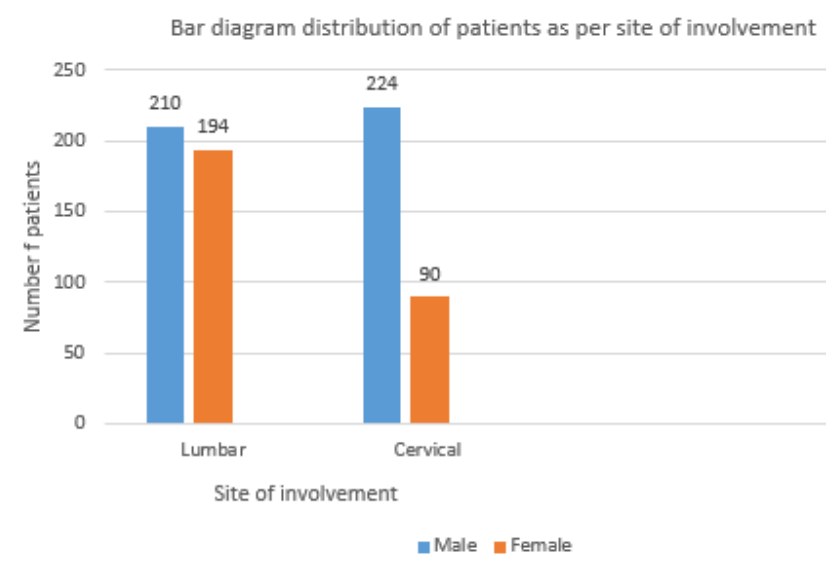

Figure4. Bar diagram showing distribution of patients as per area of involvement 
Pie diagram shwing dietary status

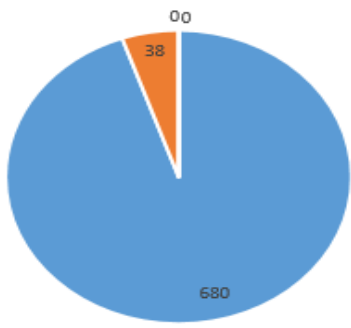

- Nonveg - pure veg

Figure5. Pie diagram showing dietary status

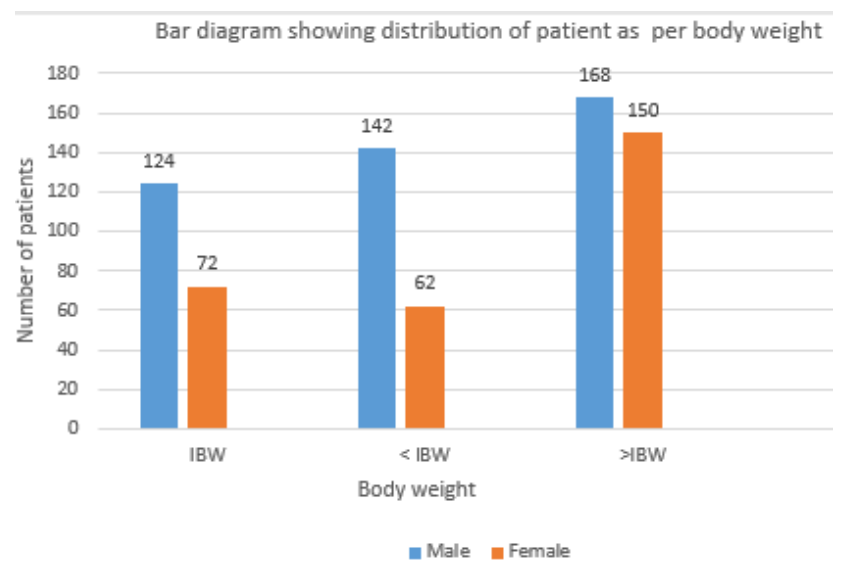

Figure6. Distribution of patients as per body weight

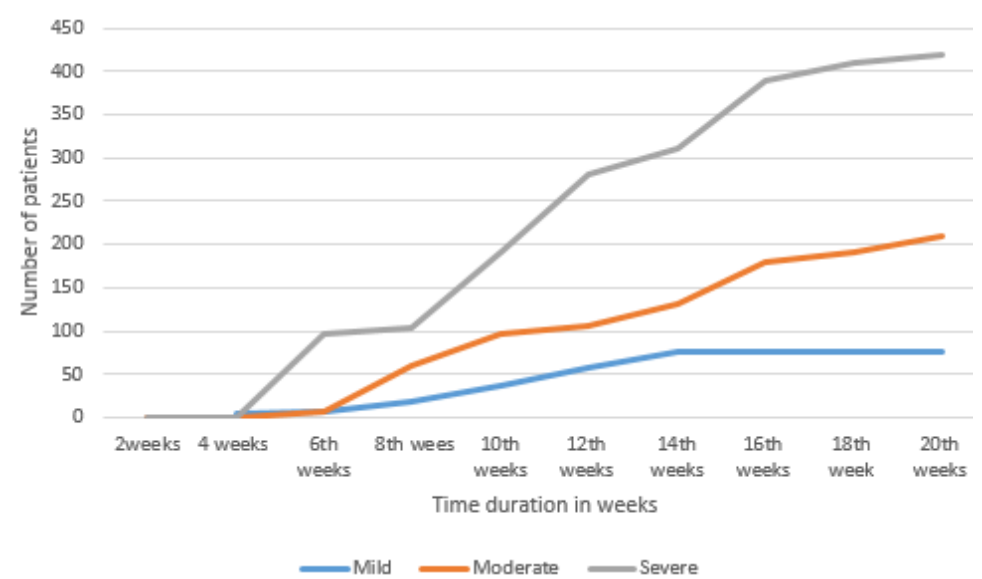

Figure7. Graph showing duration of treatment for relief of presentation

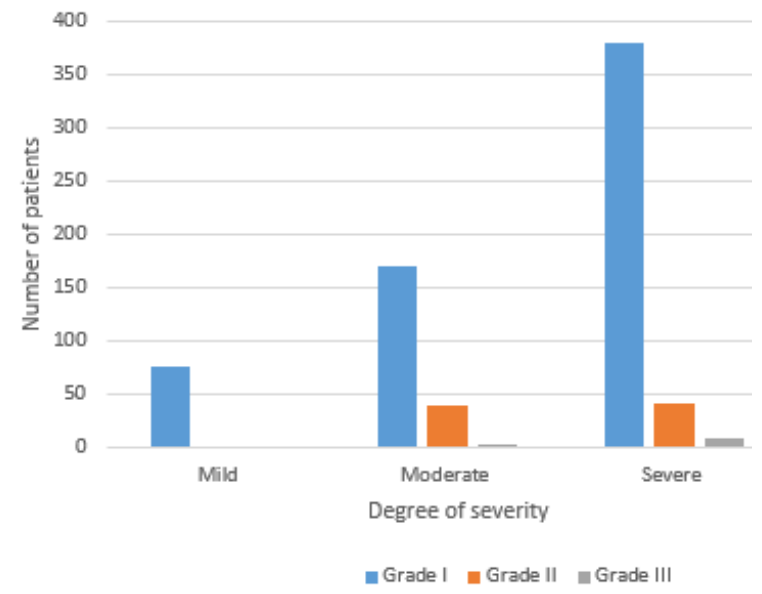

Figure8. Clinical grade of out come 
Table2. Showing out come of the study

Particulars
Clinical severity $\rightarrow$
Complete relief of presentation
Withdrawal presentation :
Radiological status:
Improved:
Un altered :
Worsen:
Post therapy bio parameters
Hepatic profile:
SGOT
<35IU
SGPT
<35IU
Alkaline phosphatase
<100
Renal parameters:
Blood urea
$<26 m g \%$
Serum creatinine
$<1.5 m g \%$
Urine:
Albumin -Negative
RBC-Negative
Haematological :
Haemoglobin
>10gm\%
Clinical grade:
Grade I
Grade II
Grade III

\begin{tabular}{|c|c|c|}
\hline \multicolumn{3}{|c|}{ Number of patients } \\
\hline Mild & Moderate & Severe \\
\hline 76 & 210 & 422 \\
\hline- & 2 & 8 \\
\hline 76 & 210 & 422 \\
\hline- & 2 & 8 \\
\hline- & - & - \\
\hline 76 & 212 & 430 \\
\hline 76 & 212 & 430 \\
\hline 76 & 212 & 430 \\
\hline 76 & 212 & 430 \\
\hline 76 & 212 & 430 \\
\hline 76 & 212 & 430 \\
\hline 76 & 212 & 430 \\
\hline 76 & 212 & 430 \\
\hline 76 & 170 & 380 \\
\hline- & 40 & 42 \\
\hline - & 02 & $\mathrm{OB}$ \\
\hline
\end{tabular}

\section{REFERENCES}

[1] M. J. HubenyRadiculitis Published Online:May 11933 https://doi.org/10.1148/20.5.331

[2] Hoy D, Brooks P, Blyth F, Buchbinder R. The Epidemiology of low back pain. Best Pract Res ClinRheumatol. 2010 Dec;24(6):769-81. [PubMed]

[3] Radhakrishnan K, Litchy WJ, O'Fallon WM, Kurland LT. Epidemiology of cervical radiculopathy: a population-based study from Rochester, Minnesota, 1976 through 1990. Brain. 1994;117(Pt 2):325-335. [PubMed] [Google Scholar]

[4] Tarulli AW, Raynor EM. Lumbosacral radiculopathy. NeurolClin. 2007 May;25(2):387-405. [PubMed]

[5] Kennedy DJ, Noh MY. The role of core stabilization in lumbosacral radiculopathy. Phys Med RehabilClin N Am. 2011 Feb;22(1):91-103. [PubMed

[6] Urits I, Burshtein A, Sharma M, Testa L, Gold PA, Orhurhu V, Viswanath O, Jones MR, Sidransky MA, Spektor B, Kaye AD. Low Back Pain, a Comprehensive Review: Pathophysiology, Diagnosis, and Treatment. Curr Pain Headache Rep. 2019 Mar 11;23(3):23. [PubMed]

[7] Nguyen HS, Doan N, Shabani S, Baisden J, Wolfla C, Paskoff G, Shender B, Stemper B. Upright magnetic resonance imaging of the lumbar spine: Back pain and radiculopathy. J Craniovertebr Junction Spine. 2016 Jan-Mar;7(1):31-7. [PMC free article] [PubMed]

[8] Al Nezari NH, Schneiders AG, Hendrick PA. Neurological examination of the peripheral nervous system to diagnose lumbar spinal disc herniation with suspected radiculopathy: a systematic review and metaanalysis. Spine J. 2013 Jun;13(6):657-74. [PubMed]

[9] Miyoshi K. [Dissociation of Anatomical (Neurological) Diagnosis and Imaging Diagnosis]. Brain Nerve. 2019 Mar;71(3):249-256. [PubMed]

[10] Wenger HC, Cifu AS. Treatment of Low Back Pain. JAMA. 2017 Aug 22;318(8):743-744. [PubMed]

[11] Ament JD, Karnati T, Kulubya E, Kim KD, Johnson JP. Treatment of cervical radiculopathy: A review of the evolution and economics. SurgNeurol Int. 2018;9:35. [PMC free article] [PubMed]

[12] Lukies MW, Teoh WW, Clements W. Safety of CT-guided cervical nerve root corticosteroid injections. J Med Imaging RadiatOncol. 2019 Mar 12; [PubMed]

[13] Mattozzi I. [Conservative treatment of cervical radiculopathy with 5\% lidocaine medicated plaster]. Minerva Med. 2015 Feb;106(1):1-7. [PubMed] 
[14] Carlesso LC, Macdermid JC, Gross AR, Walton DM, Santaguida PL. Treatment preferences amongst physical therapists and chiropractors for the management of neck pain: results of an international survey. Chiropr Man,Therap. 2014 Mar 24;22(1):11. [PMC free article] [PubMed]

[15] Ramirez MM, Brennan GP. Using the value-based care paradigm to compare physical therapy access to care models in cervical spine radiculopathy: a case report. Physiother Theory Pract. 2019 Feb 18;:1-9. [PubMed]

[16] van der Windt DA, Simons E, Riphagen II, Ammendolia C, Verhagen AP, Laslett M, Devillé W, Deyo RA, Bouter LM, de Vet HC, Aertgeerts B. Physical examination for lumbar radiculopathy due to disc herniation in patients with low-back pain. Cochrane Database Syst Rev. 2010 Feb 17;(2):CD007431. [PubMed]

[17] Shankar A etal, Tropical spastic paraparesis and Ayurveda ARC Journal of Clinical Case Reports Volume 5, Issue 2, 2019, PP 11-17

Citation: Dr. Avinash Shankar, et.al., (2019). “Radiculitis and its Current Approach”. International Journal of Clinical Chemistry and Laboratory Medicine (IJCCLM), 5(2), pp. 25-34, DOI: http://dx.doi.org/ 10.20431/2455-7153.0502005.

Copyright: (C) 2019 Authors. This is an open-access article distributed under the terms of the Creative Commons Attribution License, which permits unrestricted use, distribution, and reproduction in any medium, provided the original author and source are credited. 